\title{
ChemComm
}

Check for updates

Cite this: Chem. Commun., 2019 55, 5017

Received 17th February 2019 Accepted 4th April 2019

DOI: $10.1039 / c 9 c c 01369 e$

rsc.li/chemcomm

\section{Cobalt-doped hematite thin films for electrocatalytic water oxidation in highly acidic media $\uparrow$}

\author{
Wai Ling Kwong, (D)*a Cheng Choo Lee, ${ }^{b}$ Andrey Shchukarev ${ }^{c}$ and \\ Johannes Messinger (D) *ac
}

\begin{abstract}
Earth-abundant cobalt-doped hematite thin-film electrocatalysts were explored for acidic water oxidation. The strategically doped hematite produced a stable geometric current density of $10 \mathrm{~mA} \mathrm{~cm}$ for up to $50 \mathrm{~h}$ at $\mathrm{pH}$ 0.3, as a result of Co-enhanced intrinsic catalytic activity and charge transport properties across the film matrix.
\end{abstract}

Facile conversion of renewable solar and wind energies into chemical fuel such as $\mathrm{H}_{2}$ is an enabling technology for storing and dispatching these energies on demand and for providing off-grid utilization. Burning $\mathrm{H}_{2}$ releases energy and water without carbon emission, thus $\mathrm{H}_{2}$ is in principle a 'clean' fuel. Central to renewable energy-driven production of $\mathrm{H}_{2}$ is the electrolysis of water into $\mathrm{H}_{2}$ and $\mathrm{O}_{2}$, where acidic proton-exchange-membrane (PEM)-based water electrolyzers are known for their advantages in compact designs and high operation efficiency, relative to their alkaline counterpart. Presently, the problem for global-scale PEM water electrolysis is the lack of low-cost (earth-abundant), stable and efficient catalysts for water oxidation, i.e., oxygen-evolution reaction (OER).

Catalysts are necessary for minimizing the kinetic barriers associated with the water splitting reactions and for suppressing undesired side reactions. Presently, the materials known for efficient and stable catalysis for OER in acidic media are limited to those based on noble metals such as Ir and Ru. However, they are extremely scarce $(<0.001 \mathrm{ppm})^{1}$ in the Earth's crust and thus may not be able to provide a global-scale solution to our energy demand. The development of cost-effective catalysts from earth-abundant materials for OER in acidic media, however, is met with two major challenges: firstly, the OER is a kinetically demanding four-electron redox process, and therefore even the best catalysts would require a high voltammetric overpotential

\footnotetext{
${ }^{a}$ Department of Chemistry-Ångström Laboratory, Molecular Biomimetics, Uppsala University, 75120 Uppsala, Sweden. E-mail: WaiLing.Kwong@kemi.uu.se, Johannes.Messinger@kemi.uu.se

${ }^{b}$ Umeå Core Facility for Electron Microscopy, Umeå University, 90187 Umeå, Sweden ${ }^{c}$ Department of Chemistry, Kemiskt Biologiskt Centrum (KBC), Umeå University, 90187 Umeå, Sweden

$\dagger$ Electronic supplementary information (ESI) available. See DOI: 10.1039/c9cc01369e
}

( $>300 \mathrm{mV}$ ) to catalyze the OER at a rate equivalent to a current density of $10 \mathrm{~mA} \mathrm{~cm}^{-2}$ (characteristic operational current density for an $\sim 10 \%$ efficient solar fuel device under non-concentrated one-sun illumination); ${ }^{2}$ secondly, according to Pourbaix diagram, most earth-abundant single-metal-based materials lack innate stability against acidic corrosion at anodic potentials (viz., the applied electrical potentials necessary for OER to occur).

Various strategies have been attempted by researchers to address the above-mentioned challenges. These include the exploration of pristine as well as surface-modified transition metal-based catalysts, ${ }^{3-8}$ and the derivation of new catalysts from multi-metal oxides. ${ }^{9-13}$ The latter demonstrates the possibility of treating the catalytic activity and stability as decoupled functionalities that are facilitated by the active-yet-unstable catalytic metal and the stable-yet-inactive structural metal, respectively. Examples of such systems include CoFePbO $, \mathrm{Ni}_{x} \mathrm{Mn}_{1-x} \mathrm{Sb}_{1.6-1.8} \mathrm{O}_{y}, \mathrm{Mn}_{x} \mathrm{Sb}_{1-x} \mathrm{O}_{y}$ and F-doped $\mathrm{Cu}_{1.5} \mathrm{Mn}_{1.5} \mathrm{O}_{4}{ }^{9-11}$ While progress is being made toward producing earth-abundant catalysts for OER in acidic media, the catalysts reported thus far still lack competitive performances, in terms of activity and/or stability, as compared to the Ir- and Ru-based catalysts. Furthermore, the use of low-abundance (e.g., Sb) and/or toxic metals $(e . g ., \mathrm{Pb})$ in the catalyst composition may negatively impact the operational cost and environmental safety.

Recently, we have shown that in a mixed-polymorph catalyst film consisting of earth-abundant maghemite $\left(\gamma-\mathrm{Fe}_{2} \mathrm{O}_{3}\right)$ and hematite $\left(\alpha-\mathrm{Fe}_{2} \mathrm{O}_{3}\right)$, the $\alpha-\mathrm{Fe}_{2} \mathrm{O}_{3}$ acts as a non-catalytic scaffold that stabilizes the catalytic $\gamma-\mathrm{Fe}_{2} \mathrm{O}_{3}$ against corrosion during OER in acidic media. ${ }^{3}$ The high catalytic activity of $\gamma-\mathrm{Fe}_{2} \mathrm{O}_{3}$, as compared to $\alpha-\mathrm{Fe}_{2} \mathrm{O}_{3}$, is attributed to the inherent presence of Fe-vacancy defects, which facilitates the effective charge transport across the film and the surface adsorption of reactant water. The structural fortification by $\alpha-\mathrm{Fe}_{2} \mathrm{O}_{3}$ stems from its stability in acid and its lack of catalysis, which strengthen the $\mathrm{Fe}-\mathrm{O}$ framework around the $\gamma-\mathrm{Fe}_{2} \mathrm{O}_{3}$ active sites. This result highlights the importance of crystal defects in facilitating the electrocatalytic activity. In our continued efforts to develop acid-stable earth-abundant OER catalysts, we introduce crystal defects in $\alpha-\mathrm{Fe}_{2} \mathrm{O}_{3}$ via Co doping as a strategy to activate it for OER in acidic media. Our data show 
that a low Co doping level significantly reduces the resistance of charge transfer for OER at the film-electrolyte interface as well as charge transport across the film. The different catalytic durability of the films of varied Co doping level suggests the important role of Co in achieving a synergistic balance in relevant factors, which include the film morphology, concentration of crystal defects and thermodynamic stability, in order to obtain a maximal catalytic durability.

In this work, monometallic iron oxide $\left(\mathrm{FeO}_{y}\right)$ and bimetallic iron-cobalt oxide $\left(\mathrm{Co}_{x} \mathrm{Fe}_{1-x} \mathrm{O}_{y}\right)$ thin films were synthesized on Ti foil substrates by spray-pyrolysis deposition, followed by lowtemperature annealing in air (see $\mathrm{ESI} \dagger$ for Experimental details). The $\mathrm{FeO}_{y}$ consists of interconnected, irregularly-shaped agglomerates $(<1.5 \mu \mathrm{m})$ that are formed from individual nanograins (Fig. 1a). Smaller agglomerates are observed in the bimetallic oxide (Fig. 1b), indicating Co-induced inhibition in grain growth of the film during annealing. Aiming for minimal distortion to the crystal phase, the bimetallic oxide was synthesized at a low Co doping level (percentage of $\mathrm{Co} /(\mathrm{Co}+\mathrm{Fe}))$, which was verified by XPS to be 5 at\%, and by SEM-EDS to be 7 at\% (Fig. 1c and Table S1, ESI $\dagger$ ). For simplicity, the film is denoted as $\mathrm{Co}_{0.05} \mathrm{Fe}_{0.95} \mathrm{O}_{y}$. The mineralogy of the films, as examined by XRD (Fig. 1d), shows only diffraction peaks assigned to $\alpha-\mathrm{Fe}_{2} \mathrm{O}_{3}{ }^{14} \mathrm{~A}$ shift in the XRD peak positions in the $\mathrm{Co}_{0.05} \mathrm{Fe}_{0.95} \mathrm{O}_{y}$, relative to that in the $\mathrm{FeO}_{y}$, is hardly noticeable. However, these peaks are broader and lower in intensity, indicating a lower degree of crystallinity that may be attributed to smaller grains or crystallites, which agree with the SEM observation (Fig. 1b). Further examination of the films by Raman spectroscopy (Fig. 1e) shows the characteristic $\alpha-\mathrm{Fe}_{2} \mathrm{O}_{3}$ bands, ${ }^{15}$ in agreement with the XRD results. The Raman bands at $<600 \mathrm{~cm}^{-1}$ shift toward a higher wavenumber in $\mathrm{Co}_{0.05} \mathrm{Fe}_{0.95} \mathrm{O}_{y}$, indicating a Co-induced contraction in the chemical bonds of the $\alpha-\mathrm{Fe}_{2} \mathrm{O}_{3}$ structure. Also, the Raman band at $658 \mathrm{~cm}^{-1}$, which usually is ascribed to the crystal lattice disorder, ${ }^{16}$ presents in $\mathrm{Co}_{0.05} \mathrm{Fe}_{0.95} \mathrm{O}_{y}$, corroborating the incorporation of Co into the $\alpha-\mathrm{Fe}_{2} \mathrm{O}_{3}$ structure. A TEM-EDS mapping of the $\mathrm{Co}_{0.05} \mathrm{Fe}_{0.95} \mathrm{O}_{y}$ (Fig. S1a, ESI $\dagger$ ) shows a
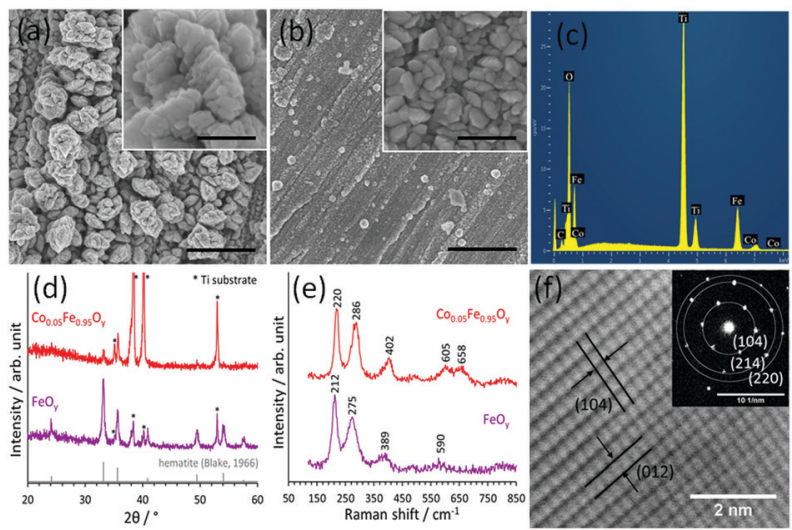

Fig. 1 Top-view SEM images of (a) $\mathrm{FeO}_{y}$ and (b) $\mathrm{Co}_{0.05} \mathrm{Fe}_{0.95} \mathrm{O}_{y}$. Scale bars: $2 \mu \mathrm{m}$; inset $200 \mathrm{~nm}$. (c) SEM-EDS of $\mathrm{CO}_{0.05} \mathrm{Fe}_{0.95} \mathrm{O}_{y}$. (d) XRD and (e) Raman spectra of $\mathrm{FeO}_{y}$ and $\mathrm{CO}_{0.05} \mathrm{Fe}_{0.95} \mathrm{O}_{y}$. ${ }^{*}$ marks the XRD peaks due to the Ti substrate. Reference XRD pattern for hematite $\left(\alpha-\mathrm{Fe}_{2} \mathrm{O}_{3}\right)$ also is shown. (f) STEM image and NBD pattern (inset) of $\mathrm{CO}_{0.05} \mathrm{Fe}_{0.95} \mathrm{O}_{y}$. homogeneous distribution of $\mathrm{Fe}$, $\mathrm{Co}$ and $\mathrm{O}$ across the film crosssection, which complements the surface elemental mapping by SEM-EDS (Fig. S1b, ESI $\dagger$ ). Both NBD and STEM data (Fig. 1f) show lattice spacings that correspond to the (104), (214), (220) and (012) planes of $\alpha-\mathrm{Fe}_{2} \mathrm{O}_{3}$, suggesting the substitutional Co doping in the $\alpha-\mathrm{Fe}_{2} \mathrm{O}_{3}$ structure.

The catalytic performance of the films for OER in $0.5 \mathrm{M}$ $\mathrm{H}_{2} \mathrm{SO}_{4}$ (pH 0.3) aqueous electrolyte is shown in Fig. 2. The OER activity of $\mathrm{CoO}_{y}$ (characterized as amorphous $\mathrm{Co}_{3} \mathrm{O}_{4}$; see Fig. S2, $\mathrm{ESI} \dagger$ ) and $\mathrm{IrO}_{y}$ also are included for comparison (see Experimental section, ESI $\nmid$ for synthesis details). The $\mathrm{Co}_{0.05} \mathrm{Fe}_{0.95} \mathrm{O}_{y}$ is OER-active and produces a geometric current density $j=10 \mathrm{~mA} \mathrm{~cm}{ }^{-2}$ at an overpotential $\eta=650 \mathrm{mV}$, while the $\mathrm{FeO}_{y}$ displays negligible $j$ within the applied potential window of $E=1.2-2.2 \mathrm{~V} v s$. RHE (Fig. 2a), which agrees with our previous study that $\alpha-\mathrm{Fe}_{2} \mathrm{O}_{3}$ film is intrinsically a poor electrocatalyst for OER in acidic electrolyte. ${ }^{3}$ Although the $\mathrm{CoO}_{y}$ is the most OER-active noble-metal-free catalyst in this work (inset in Fig. 2a), it exhibits only a short-term catalytic stability as indicated by the decreasing $j$ with the increasing CV scan number, and thus is a poor catalyst for practical operation. The $\mathrm{Co}_{0.05} \mathrm{Fe}_{0.95} \mathrm{O}_{y}$ is intrinsically more active than the $\mathrm{FeO}_{y}$, as evidenced by its relatively low Tafel slope $\left(110 \mathrm{mV} \mathrm{dec}^{-1}\right.$, which approaches that of the $\mathrm{CoO}_{y}$; Fig. 2b) and a high $j_{\text {rsa }}$ (current density normalized by the sample real surface area; Fig. S3, ESI $\dagger$ ). This may be explained by its enhanced surface adsorption of reactant water and an effective charge transport across the film. The latter is corroborated by the Nyquist plots shown in Fig. 2c, where two time-constants, represented by two consecutive semicircular curves, are observed (see Fig. S4, ESI $\dagger$ for additional Nyquist plot of $\mathrm{FeO}_{y}$ ). The semicircles in the lowand high-frequency region (i.e., the high- and low- $Z$ ' region) arise due to the resistance of charge transfer at the film-electrolyte interface $\left(R_{\mathrm{ct}}\right)$ and across the film $\left(R_{2}\right)$, respectively. Both $R_{\mathrm{ct}}$ and
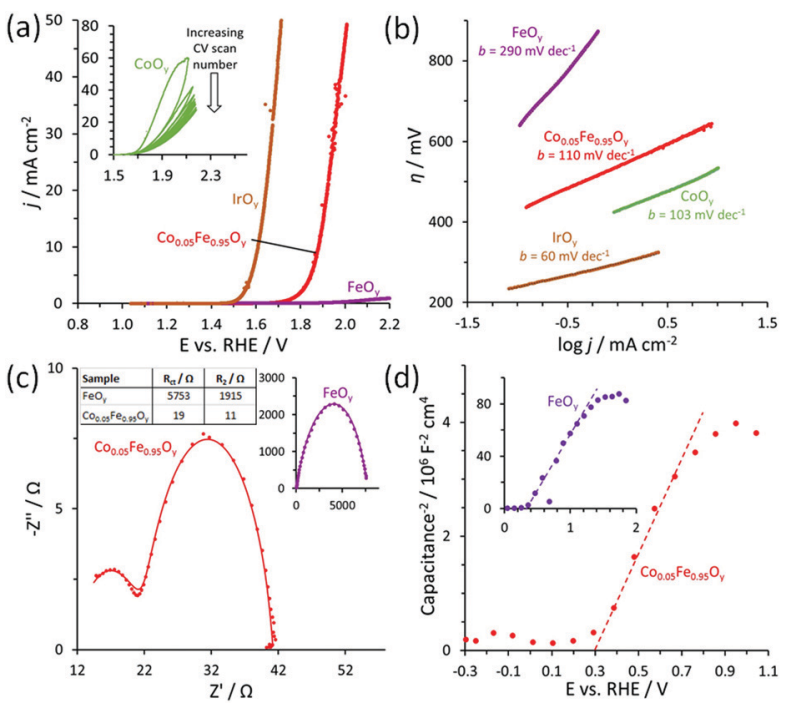

Fig. 2 Catalytic measurements at $\mathrm{pH}$ 0.3. (a) Polarization curves and (b) corresponding Tafel plots (Tafel slopes $b$ are shown). $\mathrm{IrO}_{y}$ is shown as the bench-marking catalyst. (c) Nyquist plots at $E=1.89 \mathrm{~V} v$ s. RHE (before correction for uncompensated cell resistance). (d) Mott-Schottky plots. 
$R_{2}$ values, fitted using the equivalent circuit in Fig. S5 ( $\mathrm{ESI} \dagger$ ), are significantly lower for the $\mathrm{Co}_{0.05} \mathrm{Fe}_{0.95} \mathrm{O}_{y}$ as compared to that of the $\mathrm{FeO}_{y}$, thus indicating that $\mathrm{Co}$ improves the catalytic activity and charge transport of the film, where the latter minimizes the energy loss due to potential drop across the film.

The surface chemical analysis by XPS (Fig. 3) shows that both $\mathrm{FeO}_{y}$ and $\mathrm{Co}_{0.05} \mathrm{Fe}_{0.95} \mathrm{O}_{y}$ exhibit $\mathrm{Fe} 2 \mathrm{p}$ and $\mathrm{O}$ 1s core peaks that are similar to that of $\alpha-\mathrm{Fe}_{2} \mathrm{O}_{3} \cdot{ }^{17,18}$ For the $\mathrm{Co}_{0.05} \mathrm{Fe}_{0.95} \mathrm{O}_{y}$, the peak at binding energy of $780.8 \mathrm{eV}$ matches well with the $\mathrm{Co}^{2+}$ peak of $\mathrm{CoO}_{y}$ (Fig. S2, ESI $\dagger$ ) and thus suggests that the Co dopants are present as $\mathrm{Co}^{2+},{ }^{19,20}$ which agrees well with assignments made in previous studies of Co-doped $\alpha-\mathrm{Fe}_{2} \mathrm{O}_{3}{ }^{21,22}$ The aliovalent Co doping may be charge-compensated via $\mathrm{O}$ vacancy formation, viz., $2 \mathrm{Co}_{\mathrm{Co}}^{\times} \stackrel{\mathrm{Fe}_{2} \mathrm{O}_{3}}{\longrightarrow} 2 \mathrm{Co}_{\mathrm{Fe}}^{\prime}+\mathrm{V}_{\mathrm{o}}^{\bullet \bullet}$, where $\mathrm{Co}_{\mathrm{Co}}^{\times}, \mathrm{Co}_{\mathrm{Fe}}^{\prime}$ and $\mathrm{V}_{\mathrm{o}}^{\bullet \bullet}$ are the $\mathrm{Co}$ ion on the Co lattice site (neutral charge), the Co ion on the $\mathrm{Fe}$ lattice site (single negative charge) and the $\mathrm{O}$ vacancy (double positive charge), respectively. This is evidenced in the higher surface-adsorbed $\mathrm{OH}$-to-lattice $\mathrm{O}$ peak area ratios (Table S2, ESI $\dagger$ ) of the $\mathrm{Co}_{0.05} \mathrm{Fe}_{0.95} \mathrm{O}_{y}$ (i.e., 0.28) as compared to that of the $\mathrm{FeO}_{y}$ (i.e., 0.20 ), where the formation of surface-adsorbed $\mathrm{OH}$ is attributed to the presence of $\mathrm{O}$ vacancies, ${ }^{23,24}$ which facilitate dissociative water adsorption. $^{25}$

$\mathrm{O}$ vacancies are known to act as donors in n-type hematite semiconductor (electron as the majority charge carrier). ${ }^{26}$ In contrast, the alternative mechanism for charge compensation via electron-hole formation (i.e., electronic compensation) would lead to a decreased donor density. To further test the charge compensation mechanism required to compensate for aliovalent doping, the donor densities of the films are probed by Mott-Schottky measurements as shown in Fig. 2d. We observe positive slopes in the linear region of the plots, meaning that both films display n-type semiconducting properties. ${ }^{27}$ The slope value, which is significantly lower upon Co-doping, is inversely proportional to the donor concentration in a semiconductor. $^{27}$ This shows that the density of free electrons of the $\mathrm{Co}_{0.05} \mathrm{Fe}_{0.95} \mathrm{O}_{y}$ is remarkably higher as compared to that of the $\mathrm{FeO}_{y}$, confirming the $\mathrm{O}$ vacancies formation as the major charge compensation mechanism and as the factor to its improved charge transport properties. In addition, Co doping may also improve the charge transport properties by increasing the density of localized states near the Fermi level, which is supported by the theoretical work from Liao et al. ${ }^{28}$ Our observation also
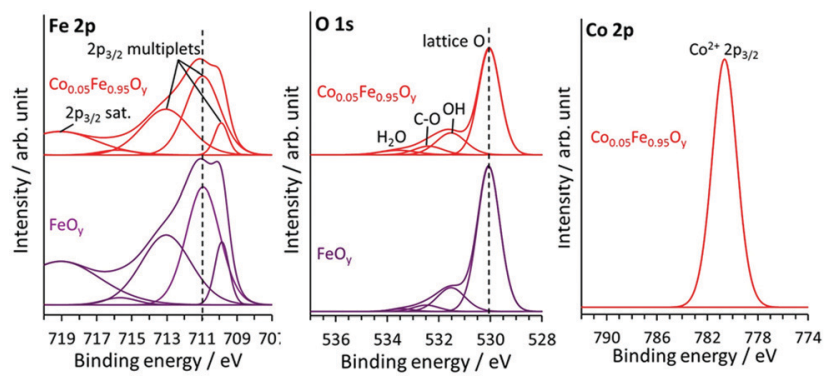

Fig. 3 High-resolution XPS spectra of $\mathrm{FeO}_{y}$ and $\mathrm{CO}_{0.05} \mathrm{Fe}_{0.95} \mathrm{O}_{y}$ in $\mathrm{Fe}$ $2 \mathrm{p}, \mathrm{O} 1 \mathrm{~s}$ and Co $2 \mathrm{p}$ regions. agrees with their calculation that Co doping improved the reaction thermodynamics of hematite for OER. ${ }^{28}$ The improvement was due to the less-positive charge of $\mathrm{Co}(2+)$ as compared to $\mathrm{Fe}(3+)$, which optimizes the binding strengths of (and thus stabilizes) the intermediate adsorbates (i.e., $\mathrm{O}^{*},{ }^{*} \mathrm{OH}$ and $\left.{ }^{*} \mathrm{OOH}\right)$ on the Co-doped hematite surface.

The flat-band potential $E_{\mathrm{fb}}$ (obtained by extrapolating the linear curve in Fig. $2 \mathrm{~d}$ to the $x$-abscissa) of the $\mathrm{FeO}_{y}$ is found at $0.30 \mathrm{~V} v s$. RHE while that of the $\mathrm{Co}_{0.05} \mathrm{Fe}_{0.95} \mathrm{O}_{y}$ is at $0.25 \mathrm{~V} v$ s. RHE. It is known that, at potentials positive of the $E_{\mathrm{fb}}$ of an n-type semiconductor, a space-charge region (SCR), i.e., depletion layer, is present within the semiconductor at the semiconductor-electrolyte interface. ${ }^{27}$ The electric field associated with the SCR is crucial, particular in photoelectrocatalysis, for separating the photogenerated excitons, where the electron-holes are driven toward oxidative reaction at the semiconductor-electrolyte interface, while the electrons migrate into the semiconductor bulk. The negative shift in the $E_{\mathrm{fb}}$ of the $\mathrm{Co}_{0.05} \mathrm{Fe}_{0.95} \mathrm{O}_{y}$ relative to that of the $\mathrm{FeO}_{y}$, implies that, under oxidative potential for $\operatorname{OER}\left(E>E_{\mathrm{fb}}\right)$, a stronger electric field forms in the SCR in $\mathrm{Co}_{0.05} \mathrm{Fe}_{0.95} \mathrm{O}_{y}$, which may facilitate the flow of electrons from the surface active sites into the film matrix.

To study the effect of Co content, the bimetallic oxide films of Co doping level 2-12 at\% (as determined by XPS and SEMEDS; see Table S1, ESI $\dagger$ ) also were synthesized. The XRD, Raman and XPS data (Fig. S6, ESI $\dagger$ ) of the films show $\mathrm{Co}^{2+}$ substitutional doping in the $\alpha-\mathrm{Fe}_{2} \mathrm{O}_{3}$ structure. A higher geometric as well as intrinsic OER activities are obtained in the bimetallic oxide film of a higher Co content (Fig. 4a and Fig. S7, ESI $\dagger$ ). The catalytic durability, viz., overpotential, of the films to maintain $j=10 \mathrm{~mA} \mathrm{~cm}{ }^{-2}$ is measured, as shown in Fig. $4 \mathrm{~b}$. While all bimetallic oxide films are OER-active, the moderately doped $\mathrm{Co}_{0.05} \mathrm{Fe}_{0.95} \mathrm{O}_{y}$ is found to be most stable (Fig. 4a), operating at $\mathrm{pH} 0.3$ for up to $50 \mathrm{~h}$ and its overpotential rises rapidly thereafter due to corrosion, which is related to the weakening and subsequent dissolution of the metal-oxygen framework caused by proton attack. It also exhibits a near-100\% Faradaic charge-to- $\mathrm{O}_{2}$ conversion efficiency (Fig. S8, ESI; $\dagger$ measured up to $2 \mathrm{~h}$ ). As expected, lowering the proton concentration (viz., at $\mathrm{pH} 2$ ) in the electrolyte results in a higher catalytic stability in $\mathrm{Co}_{0.05} \mathrm{Fe}_{0.95} \mathrm{O}_{y}$ for up to $85 \mathrm{~h}$ (Fig. 4b). As shown in Table S3 (ESI $\dagger$ ), the performance of $\mathrm{Co}_{0.05} \mathrm{Fe}_{0.95} \mathrm{O}_{y}$ is comparable to that of the recently reported
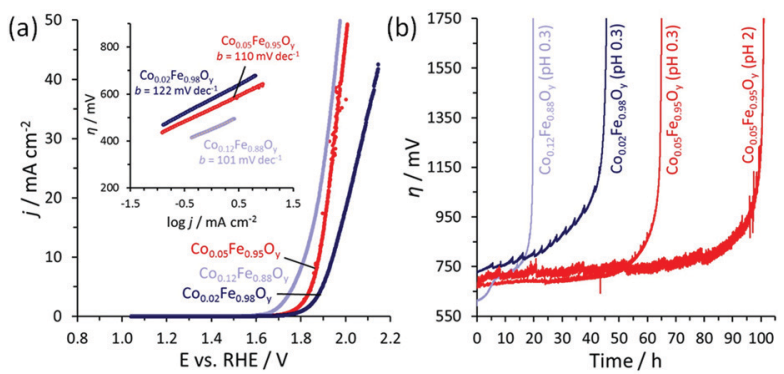

Fig. 4 (a) Polarization curves and corresponding Tafel plots of $\mathrm{Co}_{x} \mathrm{Fe}_{1-x} \mathrm{O}_{y}$. (b) Chronopotentiometric measurements of $\mathrm{Co}_{x} \mathrm{Fe}_{1-x} \mathrm{O}_{y}$ at $j=10 \mathrm{~mA} \mathrm{~cm}{ }^{-2}$ and at $\mathrm{pH} 0.3$ or $\mathrm{pH} 2$. 
noble-metal-free catalysts. The relatively low catalytic durability of the more heavily doped $\mathrm{Co}_{0.12} \mathrm{Fe}_{0.88} \mathrm{O}_{y}$ (operates at $\mathrm{pH} 0.3$ for up to $12 \mathrm{~h}$ ) is possibly due to (i) its larger electrochemically active surface area (associated to its smaller agglomerate-morphology; see Fig. S9, ESI $\dagger$ ) and thus being more exposed to proton attack, and (ii) the increased grain boundary area associated with the high number of surface defects, which are prone to corrosion. ${ }^{7}$ Since the stability of a catalyst also is influenced by the thermodynamic properties associated to the applied electrochemical potential, it is thus likely that the higher applied potential required to generate the same $j$ by the more lightly doped $\mathrm{Co}_{0.02} \mathrm{Fe}_{0.98} \mathrm{O}_{y}$ (due to its lower OER activity) promotes transformation of the catalyst to soluble species, ${ }^{29,30}$ leading to its relatively low catalytic durability (operates at $\mathrm{pH} 0.3$ for up to $28 \mathrm{~h}$ ). Future study under in operando condition is anticipated to reveal more information regarding the structure-stability correlation in the bimetallic oxides.

In summary, Co doping (2-12 at\%) has been shown to be effective in activating $\alpha-\mathrm{Fe}_{2} \mathrm{O}_{3}$ thin-film electrode for electrocatalytic OER via water oxidation in acidic electrolyte. Pristine $\alpha-\mathrm{Fe}_{2} \mathrm{O}_{3}$ and $\mathrm{Co}_{3} \mathrm{O}_{4}$, on the other hand, are inactive and unstable for OER under the same operational condition, respectively. 5 at\% Co-doped $\alpha-\mathrm{Fe}_{2} \mathrm{O}_{3}$ shows a balanced optimizations of catalytic activity (similar level of intrinsic activity as that of $\mathrm{Co}_{3} \mathrm{O}_{4}$ ) and durability (up to $50 \mathrm{~h}$ and $85 \mathrm{~h}$ at $j=10 \mathrm{~mA} \mathrm{~cm}{ }^{-2}$ at pH 0.3 and pH 2, respectively), while lower (2 at\%) and higher (12 at\%) Co doping levels result in an inferior intrinsic activity and/or durability. The catalytic activation of $\alpha-\mathrm{Fe}_{2} \mathrm{O}_{3}$ is due to Co-induced improvements in the intrinsic catalytic activity and the electron transport properties across the film, which agree with the theoretical work by Liao et al. that Co mediates the binding strengths of intermediate species leading to improved OER kinetics at the Co-doped $\alpha-\mathrm{Fe}_{2} \mathrm{O}_{3}$ surface. ${ }^{28}$ Furthermore, the interfacial transport of electrons from the surface active sites into the film may be enhanced by the stronger electric field associated with the depletion layer near the surface of Co-doped $\alpha-\mathrm{Fe}_{2} \mathrm{O}_{3}$ as compared to pristine $\alpha-\mathrm{Fe}_{2} \mathrm{O}_{3}$. The improved electron transport in the film of Co-doped $\alpha-\mathrm{Fe}_{2} \mathrm{O}_{3}$ is attributed to the increased densities of free electrons as well as localized states near the Fermi level. We have shown in this work that acidstable host materials can be catalytically activated via suitable chemical doping, and this may serve as a promising strategy to develop acid-stable OER catalysts from noble-metal-free materials.

This work was funded by Uppsala University. We thank Lars Riekehr (Uppsala University) for TEM data acquisition. We acknowledge the support from the Angström Microstructure Laboratory and the Röntgenlab at the Department of ChemistryÅngström at Uppsala University, and the Umeå Core Facility for Electron Microscopy (UCEM-NMI node) and XPS Platform at the Chemical Biological Centre (KBC) at Umeå University.

\section{Conflicts of interest}

There are no conflicts to declare.

\section{Notes and references}

1 S. R. Taylor, Geochim. Cosmochim. Acta, 1964, 28, 1273-1285.

2 C. C. L. McCrory, S. Jung, I. M. Ferrer, S. M. Chatman, J. C. Peters and T. F. Jaramillo, J. Am. Chem. Soc., 2015, 137, 4347-4357.

3 W. L. Kwong, C. C. Lee, A. Shchukarev, E. Björn and J. Messinger, J. Catal., 2018, 365, 29-35.

4 J. S. Mondschein, J. F. Callejas, C. G. Read, J. Y. C. Chen, C. F. Holder, C. K. Badding and R. E. Schaak, Chem. Mater., 2017, 29, 950-957.

$5 \mathrm{~J}$. Wu, M. Liu, K. Chatterjee, K. P. Hackenberg, J. Shen, X. Zou, Y. Yan, J. Gu, Y. Yang, J. Lou and P. M. Ajayan, Adv. Mater. Interfaces, 2016, 3, 1500669.

6 H. Schäfer, K. Küpper, M. Schmidt, K. Müller-Buschbaum, J. Stangl, D. Daum, M. Steinhart, C. Schulz-Kölbel, W. Han, J. Wollschläger, U. Krupp, P. Hou and X. Liu, Catal. Sci. Technol., 2018, 8, 2104-2116.

7 R. Frydendal, E. A. Paoli, I. Chorkendorff, J. Rossmeisl and I. E. L. Stephens, Adv. Energy Mater., 2015, 5, 1500991.

8 X. Yang, H. Li, A.-Y. Lu, S. Min, Z. Idriss, M. N. Hedhili, K.-W. Huang, H. Idriss and L.-J. Li, Nano Energy, 2016, 25, 42-50.

9 M. Huynh, T. Ozel, C. Liu, E. C. Lau and D. G. Nocera, Chem. Sci., 2017, 8, 4779-4794.

10 I. A. Moreno-Hernandez, C. A. MacFarland, C. G. Read, K. M. Papadantonakis, B. S. Brunschwig and N. S. Lewis, Energy Environ. Sci., 2017, 10, 2103-2108.

11 L. Zhou, A. Shinde, J. H. Montoya, A. Singh, S. Gul, J. Yano, Y. Ye, E. J. Crumlin, M. H. Richter, J. K. Cooper, H. S. Stein, J. A. Haber, K. A. Persson and J. M. Gregoire, ACS Catal., 2018, 8, 10938-10948.

12 P. P. Patel, M. K. Datta, O. I. Velikokhatnyi, R. Kuruba, K. Damodaran, P. Jampani, B. Gattu, P. M. Shanthi, S. S. Damle and P. N. Kumta, Sci. Rep., 2016, 6, 28367.

13 K.-L. Yan, J.-Q. Chi, J.-Y. Xie, B. Dong, Z.-Z. Liu, W.-K. Gao, J.-H. Lin, Y.-M. Chai and C.-G. Liu, Renewable Energy, 2018, 119, 54-61.

14 R. L. Blake, R. E. Hessevick, T. Zoltai and L. W. Finger, Am. Mineral., 1966, 51, 123-129.

15 N. M. A. Rashid, C. Haw, W. Chiu, N. H. Khanis, A. Rohaizad, P. Khiew and S. A. Rahman, CrystEngComm, 2016, 18, 4720-4732.

16 I. V. Chernyshova, M. F. Hochella Jr and A. S. Madden, Phys. Chem. Chem. Phys., 2007, 9, 1736-1750.

17 A. P. Grosvenor, B. A. Kobe, M. C. Biesinger and N. S. McIntyre, Surf. Interface Anal., 2004, 36, 1564-1574.

18 R. M. Cornell and U. Schwertmann, The Iron Oxides. Structure, Properties, Reactions, Occurrences and Uses, Wiley-VCH, Weinheim, 2003.

19 S. C. Petitto and M. A. Langell, J. Vac. Sci. Technol., A, 2004, 22, 1690-1696. 20 M. C. Biesinger, B. P. Payne, A. P. Grosvenor, L. W. M. Lau, A. R. Gerson and R. S. C. Smart, Appl. Surf. Sci., 2011, 257, 2717-2730.

21 J. Wang, C. Du, Q. Peng, J. Yang, Y. Wen, B. Shan and R. Chen, Int. J. Hydrogen Energy, 2017, 42, 29140-29149.

22 Y. Hou, F. Zuo, A. Dagg and P. Feng, Angew. Chem., Int. Ed., 2013, 52, 1248-1252.

23 R. Schaub, P. Thostrup, N. Lopez, E. Lægsgaard, I. Stensgaard, J. K. Nørskov and F. Besenbacher, Phys. Rev. Lett., 2001, 87, 266104.

24 R. Ovcharenko, E. Voloshina and J. Sauer, Phys. Chem. Chem. Phys., 2016, 18, 25560-25568.

25 A. Y. Al-Baitai, Doctoral, University College London, 2011.

26 T. J. Smart and Y. Ping, J. Phys.: Condens. Matter, 2017, 29, 394006.

27 K. Gelderman, L. Lee and S. W. Donne, J. Chem. Educ., 2007, 84, 685-688.

28 P. Liao, J. A. Keith and E. A. Carter, J. Am. Chem. Soc., 2012, 134, 13296-13309.

29 K. A. Persson, B. Waldwick, P. Lazic and G. Ceder, Phys. Rev. B: Condens. Matter Mater. Phys., 2012, 85, 235438.

30 A. Jain, S. P. Ong, G. Hautier, W. Chen, W. D. Richards, S. Dacek, S. Cholia, D. Gunter, D. Skinner, G. Ceder and K. A. Persson, APL Mater., 2013, 1, 011002. 